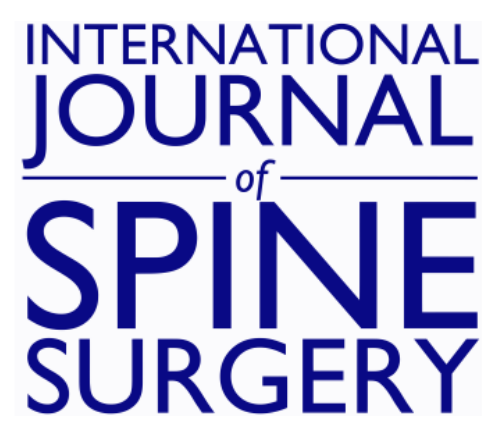

\title{
Role of Robotics in Adult Spinal Deformity
}

Patrick K. Cronin, Kornelis Poelstra and Themistocles S. Protopsaltis

Int J Spine Surg 2021, 15 (s2) S56-S64

doi: https://doi.org/10.14444/8140

http://ijssurgery.com/content/15/s2/S56

This information is current as of April 26, 2023.

Email Alerts Receive free email-alerts when new articles cite this article. Sign up at: http://ijssurgery.com/alerts 


\title{
Role of Robotics in Adult Spinal Deformity
}

\author{
PATRICK K. CRONIN, MD,${ }^{1}$ KORNELIS POELSTRA, MD, PHD ${ }^{2}$ THEMISTOCLES S. PROTOPSALTIS, MD \\ ${ }^{I}$ Division of Spine Surgery, Department of Orthopaedic Surgery, NYU Langone Medical Center, New York, New York, ${ }^{2}$ ALLEGIANT Spine Institute, \\ Las Vegas, Nevada
}

\begin{abstract}
Robotic-assisted adult deformity surgery has played a rapidly expanding role since its introduction. As robotic spine technologies improve, the potential to limit complications and morbidity is vast. The improvements in instrumentation accuracy combined with the ability to maintain that accuracy in multiple positions allow creative surgical approaches and techniques that can limit operative time, blood loss, and improve outcomes. In the years to come, robotic-assisted spine surgery and navigation will likely play an expanding role that continues to be defined.
\end{abstract}

Level of Evidence: 5, expert opinion.

Special Issue Article

Keywords: navigation, robotic spine surgery

\section{HISTORICAL CONTEXT}

Over the past century, surgical treatment of spinal deformity has, through technical and technological advancements, achieved stepwise improvements in care. In the 1960 s, Harrington ${ }^{1}$ addressed the spinal deformity epidemic that accompanied polio with the development of a stainless-steel rod with hooks. In the 1980s, this system was coupled with intervertebral fusion as advocated by Moe. ${ }^{2}$ Sublaminar Luque $^{3}$ wires improved segmental control of each vertebral body by adding fixation points to the Harrington rod. In the late 1980s, the dual rod construct reported by Cotrel et $\mathrm{al}^{4}$ allowed further rotational control and reduced the need for postoperative casting and bracing. The establishment and progressive implementation of pedicle screws further improved multidimensional correction, reduced operative time, and decreased implant dislodgement. ${ }^{5,6}$ Each of these steps advanced surgical correction of spinal deformity and accompanied a change in the complication profile.

A similar change was actualized in 1995 with the introduction of computer-assisted navigation to spine surgery. ${ }^{7}$ In 2006, robotic guidance coopted navigation technology to provide mechanical support to orient implant placement into preplanned positions. $^{8,9}$ Developments in navigation and robotics fundamentally changed surgical fixation of the spine, and since introduction, the role and application of these technologies in adult deformity surgery has continued to expand.

\section{ROLES FOR NAVIGATION AND ROBOTICS IN ADULT DEFORMITY SURGERY}

\section{Instrumentation Accuracy}

Malpositioned instrumentation is a common complication in spine surgery, representing approximately half of the instrumentation-related complications that occur. ${ }^{10}$ The issue is especially pronounced in patients with spinal deformity who often require extensive, complex, constructs. ${ }^{10,11}$ Among patients who have misplaced instrumentation, as much as $27 \%$ may require implant removal. ${ }^{10}$ The removal and revision of these malpositioned implants cause notable additional cost and morbidity. ${ }^{12}$ Although the rate of pedicle breach and screw malposition decreases with experience, even seasoned surgeons misplace pedicle screws. ${ }^{13-15}$

A principal role in the implementation of navigation and robotic guidance in spinal deformity surgery has been to improve the accuracy of instrumentation. Devito et $\mathrm{al}^{16}$ performed one of the largest retrospective studies to date evaluating implant accuracy with a surgical robot, which evaluated 3271 pedicle screws in 635 patients. Of the 646 pedicle screws for which postoperative 3dimensional imaging was performed, $98 \%$ were 
acceptable (Gertzbein-Robbins scale [GRS] Grades A or B), and approximately $2 \%$ were unacceptable (GRS Grades C or D). ${ }^{16}$ One of the first randomized control trials (RCTs) to compare robotic screw placement to freehand technique showed contrasting findings. Ringel et $\mathrm{a}^{17}$ randomized 60 patients to percutaneous screw placement or to conventional open freehand technique and postoperatively assessed the position by GRS Grade. The robotic cohort had an $85 \%$ rate of acceptable screw placement compared with a $93 \%$ rate with open freehand technique. Although Ringel et $\mathrm{al}^{17}$ concluded robotic screw placement was inferior to open freehand screw placement with fluoroscopic guidance, their results were unable to be replicated in a later study out of Seoul. In that study, a RCT of 60 patients, Hyun et $\mathrm{al}^{18}$ showed all robotic screws to be acceptably placed with approximately $99 \%$ of the freehand fluoroscopically guided cohort having suitable placement.

Given the inconsistencies in these retrospective and single-center prospective studies, several metaanalyses have been performed to further elucidate the topic. Fichtner et $\mathrm{al}^{19}$ performed a systematic analysis of 2232 patients (13 703 pedicle screws) and compared navigation and freehand techniques. They found an overall revision rate of approximately $3 \%$, with lower revision rates using navigated screws $(0.4 \%$ revised) compared with screws inserted by a freehand technique $(1.14 \%$ revised $) .{ }^{19} \mathrm{~A}$ larger contemporary meta-analysis which assessed pedicle screws placed with freehand, navigation, and robotic-assisted techniques in 7095 patients showed similar improvements in postoperative revision for malpositioned pedicle screws; with lower odds ratios (ORs) when navigation $(\mathrm{OR}=0.3$ ) or robot guidance $(\mathrm{OR}=0.3)$ were used compared with freehand techniques. ${ }^{20}$

\section{Sacropelvic Fixation}

The unique biomechanical change from the mobile lumbar spine to the immobile pelvis leads to a high strain environment that is associated with pseudarthrosis and sacral pedicle screw pullout. ${ }^{21,22}$ Rigid distal fixation with purchase between the iliac tables and in the bone superior to the acetabulum counteracts the large flexion moment and cantilever forces created by long arthrodesis constructs. ${ }^{21,23}$ The Galveston technique's incorporation of iliac fixation into long fusion constructs was one of the first to provide a means to improve distal fixation and counteract these forces. ${ }^{24}$ The technique, first advocated by Allen and Ferguson ${ }^{24}$ in the 1980s, involved the use of a pilot hole created between the tables of the iliac wing that would accept an intraosseous rod to be seated into the iliac wings and bent to extend the cephalad for fixation to the remainder of the spine. This concept was improved upon by the development of iliac screws, which improved construct strength and ease of iliac fixation implementation. ${ }^{25,26}$ While exceptionally effective in adding fixation strength, standard iliac fixation can have complications such as prominence and wound breakdown. ${ }^{27}$ Standard iliac screws may require offset rod connectors to align with the main rod construct.

S2 Alar-Iliac (S2-AI) screws, described by Chang et $\mathrm{al}^{28}$ have been shown to minimize these problems. S2-AI screws have less issues with implant prominence and achieve greater insertional torque than standard iliac screws, due to the engagement of multiple cortices. ${ }^{28,29}$ Additionally, due to a starting point caudal to the superior endplate of $\mathrm{S} 1$ and lateral to the sacral midline, S2-AI screw tulips lay in line with pedicle screw tulips of the main rod construct. This alignment obviates the need for the separate incisions, subcutaneous flaps, and the rod connectors required for standard iliac screw fixation.

Early descriptions of the S2-AI screw relied upon the use of anatomic landmarks and a freehand trajectory. ${ }^{28,30}$ Using a starting point $1 \mathrm{~mm}$ inferior and lateral to the S1 dorsal foramen with the screw angulated $40^{\circ}$ inferiorly from a posterior superior iliac spine (PSIS) horizon line and $40^{\circ}$ lateral from midline. In a review of 100 S2-AI screws placed freehand by this method, approximately $5 \%$ of screws had a moderate to severe cortical breach. While these complications did not obviously have a negative effect on outcome, as no screws breached anterior to the inner table of the iliac crest and no neurologic or vascular events occurred, accuracy was acceptable, but there was room for improvement. ${ }^{30}$ Like their role in pedicle screw accuracy, robotics and navigation have been implemented to improve the accuracy of S2-AI screw placement with published accuracy rates between $96 \%$ and $100 \% .{ }^{31-33}$ Furthermore, because direct visualization is not necessary, robotic-assisted S2-AI screws are ideal for sacropelvic fixation by a percutaneous technique for minimally invasive (MIS) deformity cases. 


\section{MIS Deformity}

Progress in adult deformity surgery has been accompanied by a persistent and growing interest in reducing surgical morbidity and complications. Alongside this interest, MIS techniques have been increasingly developed and applied to adult deformity cases with the potential for lower infection rates, reduced blood loss, and need for postoperative intensive care. ${ }^{34-36}$ MIS deformity correction commonly includes MIS and hybrid (partially open) techniques. The MIS approaches involve the use of interbody devices to achieve deformity correction, arthrodesis, and indirect neurologic decompression through soft tissue sparing approaches. ${ }^{37}$ These MIS approaches frequently use percutaneous posterior screw and rod instrumentation to stabilize the construct during healing. Hybrid approaches tend to use similar MIS interbody fixation techniques for deformity correction in combination with more traditional open posterior techniques for deformity correction, fixation, and arthrodesis. ${ }^{35}$

Authors of several studies have compared MIS with hybrid deformity correction. Eastlack et $\mathrm{al}^{38}$ retrospectively reviewed 133 deformity patients treated with MIS or hybrid techniques with 2-year follow up. Among this cohort, there was a significantly lower early (less than 30 days) reoperation rate in the MIS cohort than in the hybrid cohort, respectively $0 \%$ versus $10.8 \%$. These revisions were largely due to infection. Notably, despite the MIS technique and inability to prepare the posterior bone for fusion, there was no significant difference in long-term revisions (MIS 27\% versus hybrid $22 \%$ ) due to instrumentation failure or pseudarthrosis. Uribe et al ${ }^{39}$ performed a propensity score matched analysis of 60 patients treated with MIS, hybrid, or open deformity correction surgery, which showed the MIS cohort to have lower blood loss but significantly longer operative time than the open cohort. Notably, the authors of that study did not use a single position technique for the MIS and hybrid procedures and note that this repositioning negatively affected their operative time. This conclusion is supported by the findings of Buckland et $\mathrm{al}^{40}$ who reported on their institutional experience with 390 patients treated with MIS anteroposterior fusion. In this cohort, there was a 3-hour reduction in total operative time with single-position surgery. ${ }^{40}$ Because MIS deformity correction inherently limits exposure and visualization, navigation and robotics are seen by some to have an obvious role in the potential for improved implant accuracy, reduced operative time, and lower intraoperative radiation exposure. ${ }^{41,42}$

\section{Radiation Reduction}

In addition to improvement in screw accuracy, a potential benefit of robotics is limited radiation exposure, both to the patient and to the surgical team. Several studies have compared patient fluoroscopic time and radiation exposure for screw instrumentation between fluoroscopically placed pedicle screws and robotically assisted pedicle screws. In a retrospective review of 112 consecutive patients who underwent pedicle screw instrumentation via heterogeneous techniques, patients who underwent open screw placement had significantly less intraoperative radiation. ${ }^{43}$ In that study, there was no difference in intraoperative radiation exposure between fluoroscopically assisted screw placement and robotic-assisted screw placement. However, notably, the researchers did not take radiation exposure incurred preoperatively into account. Authors of a recent review of 1202 cases with screws placed via freehand, fluoroscopically guided, navigated, and robotic-guided techniques in which preoperative radiation exposure was considered showed no difference in radiation dose when patients were propensity score matched by body mass index. ${ }^{44}$ In a prospective randomized trial, Ringel et $\mathrm{al}^{17}$ compared 152 pedicle screws placed freehand through a MIS approach with fluoroscopic guidance with 146 robotic-assisted pedicle screws, which showed no difference in intraoperative radiation exposure. These findings were supported in a recent retrospective review by Wang et al. ${ }^{45}$ Among 165 patients who were assessed after heterogenous screw insertion techniques, navigation-assisted and robotic-assisted pedicle screws had lower intraoperative and total procedure radiation than patients instrumented with a fluoroscopicassisted technique. Importantly, that study considered preoperative computed tomography (CT) scan to account for total procedure radiation, and again, robotic and navigated cases had less radiation (approximately 60 and $50 \mathrm{mGy}$, respectively) than fluoroscopically aided pedicle screws (approximately $79 \mathrm{mGy}) .{ }^{45}$ Notably, the radiation per level was also lower in the navigated (42 $\mathrm{mGy}$ ) and robotic (51 mGy) cases than in the fluoroscopy aided cases (79 $\mathrm{mGy}$ ); this could indicate that, in surgeries involving more instrumented levels, such as large 
deformity constructs, the incremental radiation dose per level becomes more favorable. ${ }^{45}$

While authors of current studies do not yet show a statistical advantage for reduced radiation exposure to the patient by robotics and navigation, the radiation exposure to the surgeon and team is greatly reduced by these technologies. Assessments of surgeon radiation exposure during fluoroscopically assisted pedicle screws have been shown to produce surgeon dose rates 10 to 12 times greater than nonfluoroscopically assisted screw placement. ${ }^{46}$ Although annual allowable occupational radiation exposure for hand dose rates of $50 \mathrm{rem}$ is generally not reached by spine surgeons, the effects of repeated low-dose radiation are still largely unknown. ${ }^{46,47}$ In the scenario that a nonoptimal fluoroscopic technique is used, it is likely that the recommended hand dose for a surgeon could be exceeded. ${ }^{46}$ Because navigation and robotic-assisted procedures allow the surgeon and team to maintain a safe distance from the radiation source, these procedures are associated with negligible levels of radiation and allow personnel to limit repeated exposure while maintaining implant accuracy.

\section{ROBOTIC SPINAL DEFORMITY SURGICAL TECHNIQUE}

Surgical workflow begins with preoperative planning including full-length standing scoliosis radiographs. Patients can be positioned in prone, singleposition prone, or single-position lateral decubitus positions depending on the specific needs of the case.

\section{Prone Positioning}

The patient is positioned using a standard 6-post Jackson frame. For thoracolumbar cases in which a fluoroscopic merge to a preoperative CT is planned, arm boards should be positioned to allow clear fluoroscopic imaging. A wide surgical field, with access to bilateral PSIS should be prepped and draped. The fiducial is placed via a stab incision into the PSIS. The trajectory and laterality of the fiducial can be changed depending on the specific case to avoid interference with the surgical approach and to optimize view of fiducial by the camera. Some robotic systems have an additional surveillance marker that can monitor displacement of the main fiducial. The surveillance marker, placed in the contralateral PSIS, provides a secondary check on registration and alerts of any shift in registration that can lead to inaccuracies. To detect any registration shifts and limit inaccuracy propagation during the merge protocol itself, the surveillance marker should be registered before the radiographic merge begins.

The radiographic merge can be achieved either with a preoperative CT merged via 2-dimensional intraoperative fluoroscopy, a preoperative CT merged via surface anatomy correlation, or intraoperative CT obtained with 1 of several different systems. If an open approach is to be performed, the surgical approach should be completed before any merge is attempted to limit registration shift that could otherwise occur during the surgical approach. Similarly, after the merge, pedicle screws should be placed before significant manipulation is performed, such as osteotomies or interbody device placement, to limit the potential for registration shift. Pedicle screws should be placed before sacropelvic fixation to limit registration shift that can occur if the fiducial and screw come into contact within the substance of the iliac bone column.

\section{Single Position Lateral}

Single-position lateral surgery has been shown to be an efficient method for thoracolumbar deformity correction while limiting operative and anesthetic time. ${ }^{33}$ This method can be effective in patients who would benefit from anterior or lateral interbody device placement in addition to pedicle screw fixation. The main limitation of single-position lateral surgery is the increased difficulty in performing significant complex posterior work. Cases requiring significant posterior work may be better addressed in the prone position.

The patient is positioned in the lateral position, as previously described, for lateral lumbar interbody fusion (LLIF). ${ }^{48,49}$ Care should be taken to prepare and drape enough of the torso to allow appropriate intraoperative access (Figure 1). If an anterior abdominal approach is planned, the abdomen from the contralateral side of the umbilicus around the lateral operative flank to contralateral (down) back exposing the PSIS closest to the operative table should be included within the operative field. The fiducial should be placed into the substance of the iliac crest midway between the ipsilateral (up) PSIS and the apex of the iliac crest at the lateral flank. The surveillance marker should be placed into the iliac crest at the apex of the flank. 


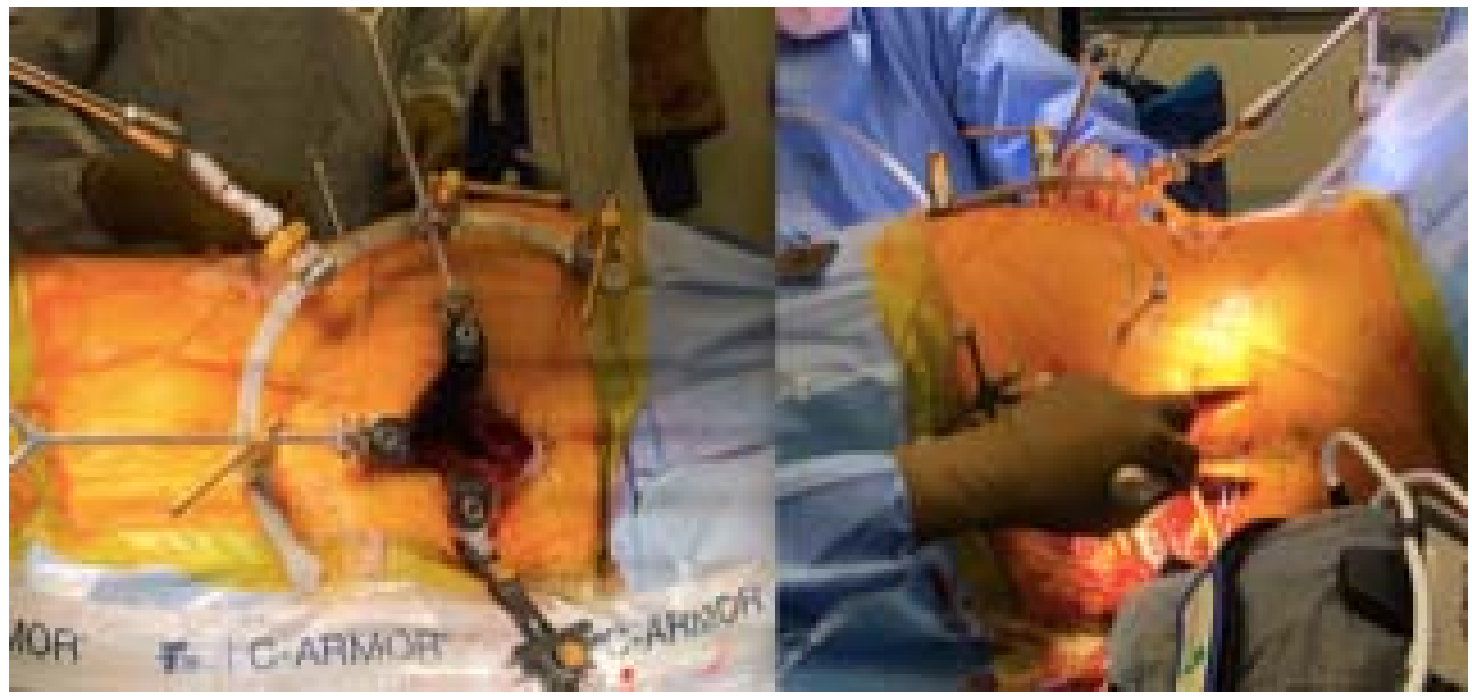

Figure 1. Draped surgical field for single-position lateral procedure with an anterior retroperitoneal lumbar approach.

Once the merge has been performed, the robot can be used on the posterior side, while concurrently an access surgeon may perform the anterior (retroperitoneal) approach to the lumbar spine, if indicated surgically (Figure 2). Pedicle screws should be placed in the contralateral (downside) pedicles first, followed by the ipsilateral (upside) pedicles to avoid obstruction of the surgical field by any incidental bleeding. Interbody device placement should be performed after the pedicle screws but before iliac screw fixation to avoid a registration shift and screw inaccuracy.

To perform LLIF itself, a retroperitoneal-transpsoas approach can be performed in the standard fasion. ${ }^{48-50}$ Navigated instruments and pointers can be used to localize and optimize the angle during the approach (Figure 3). A standard annulotomy, discectomy, and lateral interbody fusion can then

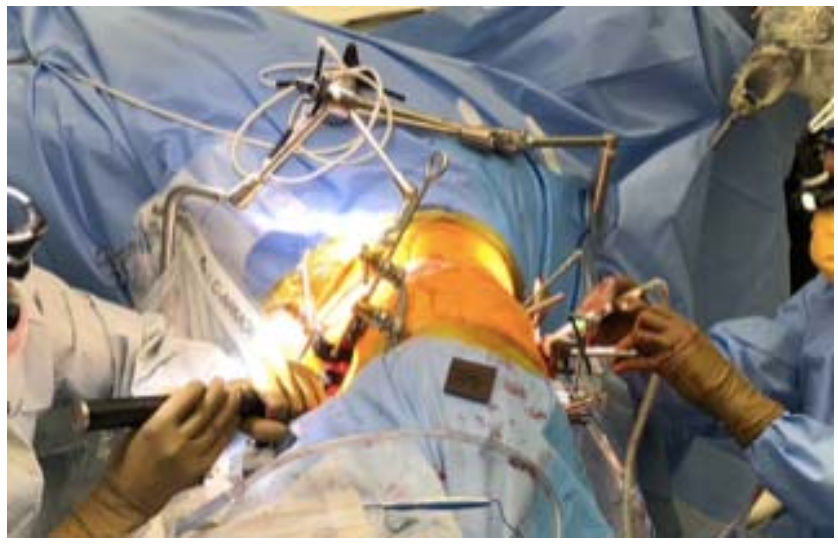

Figure 2. Single-position lateral approach allows shortened surgical time by avoiding need for bed change and allowing concurrent anterior and posterior surgery. be performed using navigated instrumentation or fluoroscopy to confirm positioning of the implants and approach. ${ }^{48,50,51}$

\section{Single Position Prone}

Single-position prone surgery may be beneficial if significant posterior work (osteotomies, decompression, or revision of previous hardware) needs to be

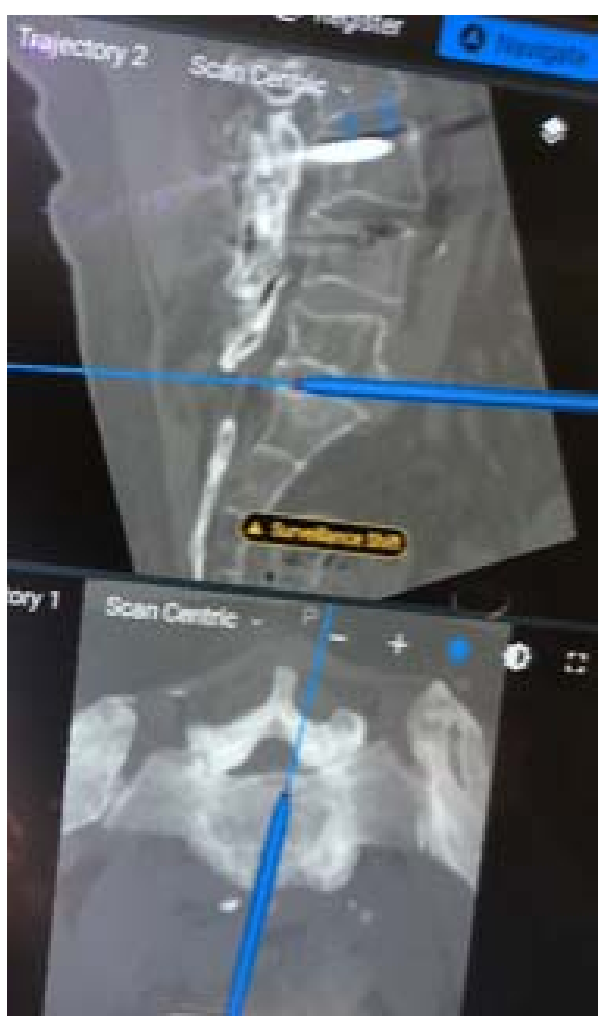

Figure 3. Navigated instruments can be used to localize and optimize angle during the approach and instrumentation. 


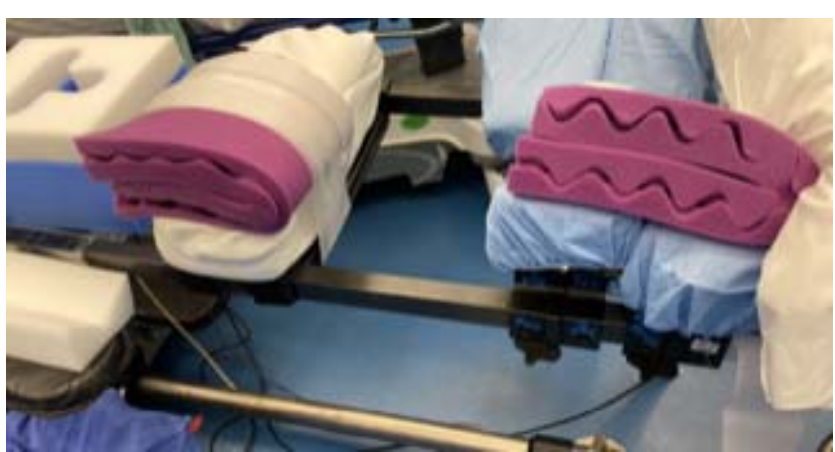

Figure 4. Asymmetrically padded chest and pelvis bolsters on the side of lateral lumbar interbody fusion (LLIF) insertion.

performed in addition to interbody device and pedicle screw placement. As in standard prone cases, in single-position prone cases, a 6-post Jackson frame can be used. It is beneficial to asymmetrically pad the chest and pelvis bolsters on the side of LLIF insertion to allow ease of access to the surgical field (Figure 4). The pelvis bolster on the implant insertion side should be positioned more caudad than the contralateral side (Figure 5); this positioning allows hyperlordosis on the approach side that mimics the tissue tension achieved in lateral position LLIFs by breaking the table. ${ }^{51,52}$ The patient should be secured thoroughly at the head, arms, chest, pelvis, and legs to allow bed rotation up to approximately $30^{\circ}$ to $45^{\circ}$. In our institution, 4-inch silk tape is used to secure the patient's chest and pelvis above and below the surgical field, respectively (Figure 6). A Mayfield head holder can also be used to assist in limiting head rotation during the operation, especially in prolonged cases, to avoid pressure on the face and eyes.

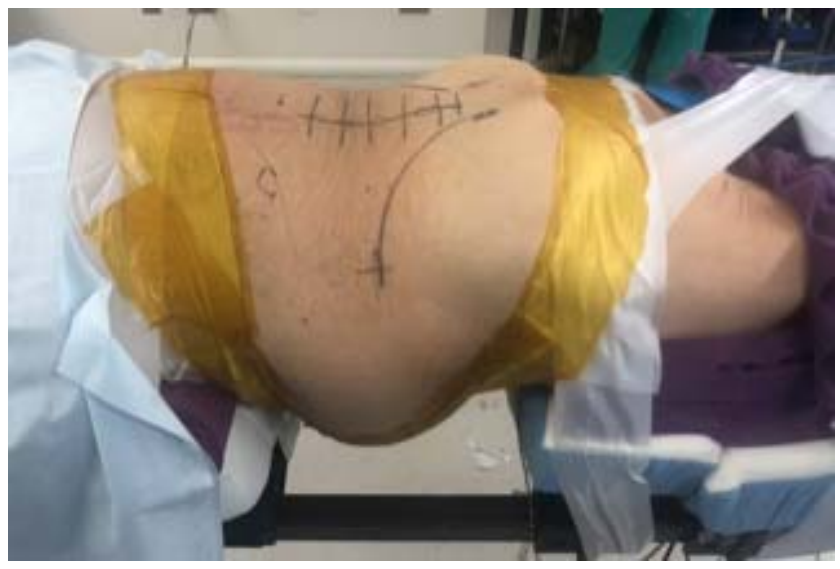

Figure 5. Pelvis bolster on the implant insertion side positioned asymmetrically caudal to facilitate hyperlordosis and tissue tension during lateral lumbar interbody fusion (LLIF).

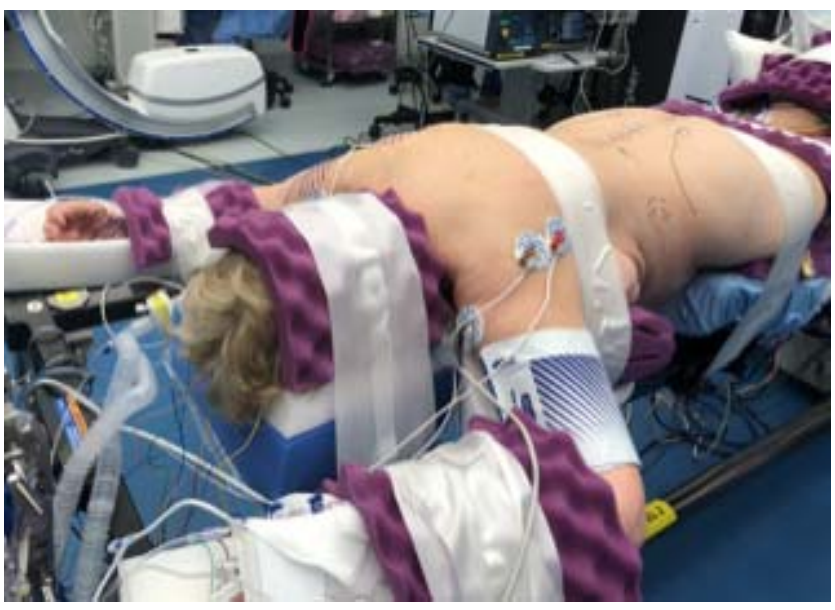

Figure 6. Patient secured thoroughly at the head, arms, chest, pelvis, and legs to allow bed rotation.

The clamp to secure the LLIF retractor is optimally positioned on the contralateral side to the LLIF insertion just below the chest bolster (Figure 7). This allows the retractor arm to remain distant from the surgical working area during the case and avoid blocking the field during the radiographic merge.

As in the single-position lateral cases, the fiducial should be placed in the iliac crest midway between the PSIS and the apex of the iliac crest at the lateral flank on the ipsilateral side to the LLIF insertion. The surveillance marker should be placed in the contralateral PSIS away from the LLIF insertion. As in standard prone positioning, the surveillance marker should be placed and registered before the merge to provide a secondary check on accuracy in

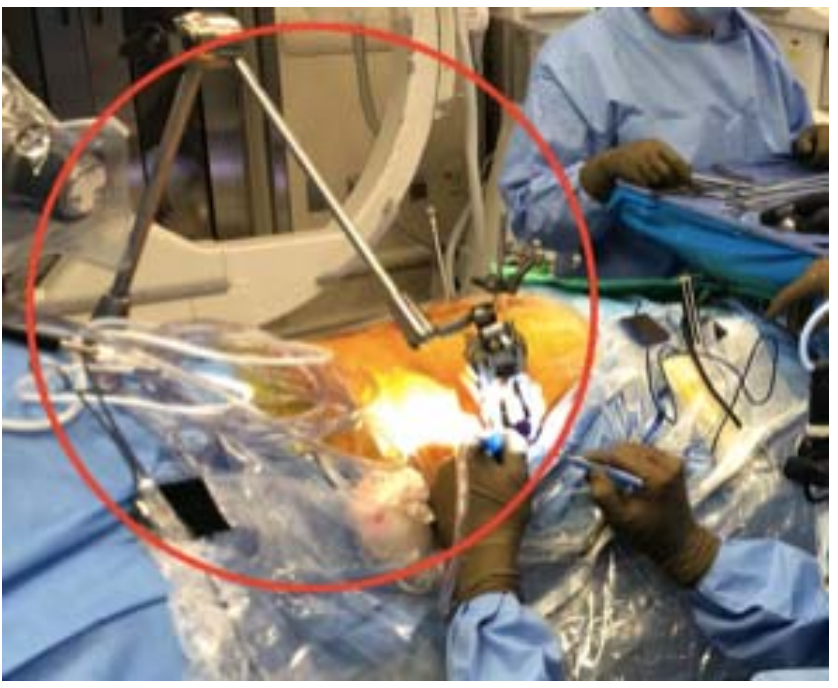

Figure 7. Positioning of the clamp for the lateral lumbar interbody fusion (LLIF) retractor positioned contralateral side to the LLIF insertion. 
the event of movement during the radiographic merge.

If a paraspinal or MIS incision is used, screw trajectory and placement can be optimized for incision length and ease of rod insertion. If screws are planned to be placed through an open midline incision, the incision and dissection should be performed before the radiographic merge to limit the opportunity for registration change during the merge process. Additionally, if a midline approach is planned, the surgical flaps should be made large enough to limit soft tissue pressure on the robotic end effector cannula, which can introduce inaccuracy during the instrumentation process. For surgical workflow, pedicle screws should again be inserted proximal to distal followed by interbody devices.

To perform LLIF in the prone position, the surgeon may stand or operate while seated on a stool using the bed rotation within the $45^{\circ}$ position arc to optimize view of the surgical field. As in the lateral position, a retroperitoneal-transpsoas approach can be performed in the standard fasion. ${ }^{48-50}$ The dilator and retractor are placed perpendicular to the long axis of the spine, respecting the safe zones with the retractor arm connected to the retractor from the contralateral side of the patient. ${ }^{33,49}$ Navigated instruments and pointers can be used to localize and optimize angle during the approach. During dilator docking, established thresholds for neuromonitoring should be used, and care should be taken to avoid docking posterior in the substance of the psoas. ${ }^{53,54}$ The psoas may have the effect of pushing the retractor more anterior than in a LLIF performed in the lateral position. A standard annulotomy, discectomy, and lateral interbody fusion can then be performed using navigated instrumentation or fluoroscopy to confirm positioning of the implants and approach. $^{48,50,51}$ Sacropelvic fixation, if used, should be placed last to avoid interference with the fiducial by the screw within the substance of the iliac crest.

\section{CONCLUSIONS}

Surgical and technological improvements have played an integral role in the successful execution of adult spinal deformity surgery throughout history. Navigation and robotic assistance represent a continuation of this process. Since introduction, navigation and robotics have occupied an expanding role in deformity surgery including improve- ments in pedicle screw accuracy, the facilitation of MIS techniques that limit dissection and operative time, and improved spinopelvic fixation that is less prominent and more rigid. While these technologies have already made a lasting impact on adult deformity surgery, they have also not yet fully matured, and further development is necessary.

\section{REFERENCES}

1. Harrington PR. Treatment of scoliosis. Correction and internal fixation by spine instrumentation. J Bone Jt Surg Am. 1962;44-A:591-610.

2. Moe JH. Modern concepts of treatment of spinal deformities in children and adults. Clin Orthop Relat Res. 1980;(150):137-153.

3. Luque ER. Segmental spinal instrumentation for correction of scoliosis. Clin Orthop Relat Res. 1982;163(1):192-198. doi:10.1097/00003086-198203000-00028

4. Cotrel Y, Dubousset J, Guillaumat M. New universal instrumentation in spinal surgery. Clin Orthop Relat Res. 1988;227:10-23

5. Suk SI, Lee CK, Kim WJ, Chung YJ, Park YB. Segmental pedicle screw fixation in the treatment of thoracic idiopathic scoliosis. Spine (Phila Pa 1976). 1995;20(12):1399-1405. doi:10. 1097/00007632-199506020-00012

6. Suk S Il, Kim W, Lee S, Kim JH, Chung E. Thoracic pedicle screw fixation in spinal deformities: are they really safe? Spine (Phila Pa 1976). 2001;26(18):2049-2057. doi:10.1097/ 00007632-200109150-00022

7. Nolte LP, Zamorano L, Visarius $\mathrm{H}$, et al. Clinical evaluation of a system for precision enhancement in spine surgery. Clin Biomech. 1995;10(6):293-303. doi:10.1016/02680033(95)00004-5

8. Lieberman IH, Togawa D, Kayanja MM, et al. Bonemounted miniature robotic guidance for pedicle screw and translaminar facet screw placement: part I-technical development and a test case result. Neurosurgery. 2006;59(3):641-650. doi:10.1227/01.NEU.0000229055.00829.5B

9. Togawa D, Kayanja MM, Reinhardt MK, et al. Bonemounted miniature robotic guidance for pedicle screw and translaminar facet screw placement: part 2-evaluation of system accuracy. Neurosurgery. 2007;60(2 Suppl 1):26-28. doi:10.1227/01.NEU.0000249257.16912.AA

10. Shillingford JN, Laratta JL, Sarpong NO, et al. Instrumentation complication rates following spine surgery: a report from the Scoliosis Research Society (SRS) morbidity and mortality database. J Spine Surg. 2019;5(1):110-115. doi:10. 21037/jss.2018.12.09

11. Li G, Lv G, Passias P, et al. Complications associated with thoracic pedicle screws in spinal deformity. Eur Spine J. 2010;19(9):1576-1584. doi:10.1007/s00586-010-1316-y

12. Larson AN, Polly DW, Guidera KJ, et al. The accuracy of navigation and $3 \mathrm{D}$ image-guided placement for the placement of pedicle screws in congenital spine deformity. $J$ Pediatr Orthop. 2012;32(6):23-29. doi:10.1097/BPO. 0b013e318263a39e

13. Lehman RA, Lenke LG, Keeler KA, Kim YJ, Cheh G. Computed tomography evaluation of pedicle screws placed in the pediatric deformed spine over an 8-year period. Spine (Phila 
Pa 1976). 2007;32(24):2679-2684. doi:10.1097/BRS. 0b013e31815a7f13

14. Gonzalvo A, Fitt G, Liew S, et al. The learning curve of pedicle screw placement: how many screws are enough? Spine (Phila Pa 1976). 2009;34(21):761-765. doi:10.1097/BRS. 0b013e3181b2f928

15. Chen G, Li H, Li F, Chen W, Chen Q. Learning curve of thoracic pedicle screw placement using the free-hand technique in scoliosis: how many screws needed for an apprentice? Eur Spine J. 2012;21(6):1151-1156. doi:10.1007/s00586-011-2065-2

16. Devito DP, Kaplan L, Dietl R, et al. Clinical acceptance and accuracy assessment of spinal implants guided with spineassist surgical robot: retrospective study. Spine (Phila $\mathrm{Pa}$ 1976). 2010;35(24):2109-2115. doi:10.1097/BRS.0b013e3181 d323ab

17. Ringel F, Stüer C, Reinke A, et al. Accuracy of robotassisted placement of lumbar and sacral pedicle screws: a prospective randomized comparison to conventional freehand screw implantation. Spine (Phila Pa 1976). 2012;37(8)E496E501. doi:10.1097/BRS.0b013e31824b7767

18. Hyun SJ, Kim KJ, Jahng TA, Kim HJ. Minimally invasive robotic versus open fluoroscopic-guided spinal instrumented fusions. Spine (Phila Pa 1976). 2017;42(6):353-358. doi:10.1097/BRS.0000000000001778

19. Fichtner J, Hofmann N, Rienmüller A, et al. Revision rate of misplaced pedicle screws of the thoracolumbar spinecomparison of three-dimensional fluoroscopy navigation with freehand placement: a systematic analysis and review of the literature. World Neurosurg. 2018;109:e24-e32. doi:10.1016/j. wneu.2017.09.091

20. Staartjes VE, Klukowska AM, Schröder ML. Pedicle screw revision in robot-guided, navigated, and freehand thoracolumbar instrumentation: a systematic review and meta-analysis. World Neurosurg. 2018;116:433-443.e8. doi:10. 1016/j.wneu.2018.05.159

21. McCord DH, Cunningham BW, Shono Y, Myers JJ, McAfee PC. Biomechanical analysis of lumbosacral fixation. Spine (Phila Pa 1976). 1992;17(8S):S235-S243.

22. Glazer PA, Colliou O, Lotz JC, Bradford DS. Biomechanical analysis of lumbosacral fixation. Spine (Phila $P a$ 1976). 1996;21(10):1211-1222. doi:10.1097/00007632199605150-00015

23. Edwards CC, Bridwell KH, Patel A, Rinella AS, Berra A, Lenke LG. Long adult deformity fusions to L5 and the sacrum: a matched cohort analysis. Spine (Phila Pa 1976). 2004;29(18):1996-2005. doi:10.1097/01.brs.0000138272.54896. 33

24. Allen BL, Ferguson RL. The Galveston technique of pelvic fixation with L-rod instrumentation of the spine. Spine (Phila Pa 1976). 1984;9(4):388-394. doi:10.1097/00007632198405000-00011

25. Schwend RM, Sluyters R, Najdzionek J. The pylon concept of pelvic anchorage for spinal instrumentation in the human cadaver. Spine (Phila Pa 1976). 2003;28(6):542-547. doi:10.1097/01.BRS.0000049925.58996.66

26. Kuklo TR, Bridwell KH, Lewis SJ, et al. Minimum 2year analysis of sacropelvic fixation and L5-S1 fusion using S1 and iliac screws. Spine (Phila Pa 1976). 2001;26(18):1976-1983. doi:10.1097/00007632-200109150-00007

27. Stevens DB, Beard C. Segmental spinal instrumentation for neuromuscular spinal deformity. Clin Orthop Relat Res. 1989;(242):164-168. doi:10.1097/00003086-198905000-00015
28. Chang TL, Sponseller PD, Kebaish KM, Fishman EK. Low profile pelvic fixation: anatomic parameters for sacral alariliac fixation versus traditional iliac fixation. Spine (Phila $\mathrm{Pa}$ 1976). 2009;34(5):436-440. doi:10.1097/BRS.0b013e318194 $128 \mathrm{c}$

29. Jain A, Hassanzadeh H, Strike SA, Menga EN, Sponseller PD, Kebaish KM. Pelvic fixation in adult and pediatric spine surgery: historical perspective, indications, and techniques AAOS exhibit selection. J Bone Jt Surg Am. 2015;97(18):1521-1528. doi:10.2106/JBJS.O.00576

30. Shillingford JN, Laratta JL, Tan LA, et al. The free-hand technique for S2-alar-iliac screw placement. J Bone Jt Surg Am. 2018;100(4):334-342. doi:10.2106/JBJS.17.00052

31. $\mathrm{Hu} \mathrm{X}$, Lieberman IH. Robotic-guided sacro-pelvic fixation using S2 alar-iliac screws: feasibility and accuracy. Eur Spine J. 2017;26(3):720-725. doi:10.1007/s00586-016-46395

32. Laratta JL, Shillingford JN, Meredith JS, Lenke LG, Lehman RA, Gum JL. Robotic versus freehand S2 alar iliac fixation: in-depth technical considerations. J Spine Surg. 2018;4(3):638-644. doi:10.21037/jss.2018.06.13

33. Jain D, Manning J, Lord E, et al. Initial single-institution experience with a novel robotic-navigation system for thoracolumbar pedicle screw and pelvic screw placement with 643 screws. Int J Spine Surg. 2019;13(5):459-463. doi:10.14444/6060

34. Anand N, Baron EM, Thaiyananthan G, Khalsa K, Goldstein TB. Minimally invasive multilevel percutaneous correction and fusion for adult lumbar degenerative scoliosis: a technique and feasibility study. J Spinal Disord Tech. 2008;21(7):459-467. doi:10.1097/BSD.0b013e318167b06b

35. Anand N, Baron EM, Kahwaty S. Evidence basis/ outcomes in minimally invasive spinal scoliosis surgery. Neurosurg Clin N Am. 2014;25(2):361-375. doi:10.1016/j.nec.2013.12. 014

36. Anand N, Baron EM, Khandehroo B, Kahwaty S. Longterm 2-to 5-year clinical and functional outcomes of minimally invasive surgery for adult scoliosis. Spine (Phila Pa 1976). 2013;38(18):1566-1575. doi:10.1097/BRS.0b013e31829cb67a

37. Isaacs RE, Hyde J, Goodrich JA, Rodgers WB, Phillips FM. A prospective, nonrandomized, multicenter evaluation of extreme lateral interbody fusion for the treatment of adult degenerative scoliosis: perioperative outcomes and complications. Spine (Phila Pa 1976). 2010;35(26 Suppl):S322-S330. doi:10.1097/BRS.0b013e3182022e04

38. Eastlack RK, Srinivas R, Mundis GM, et al. Early and late reoperation rates with various MIS techniques for adult spinal deformity correction. Glob Spine J. 2019;9(1):41-47. doi: $10.1177 / 2192568218761032$

39. Uribe JS, Deukmedjian AR, Mummaneni PV, et al. Complications in adult spinal deformity surgery: an analysis of minimally invasive, hybrid, and open surgical techniques. Neurosurg Focus. 2014;36(5):1-9. doi:10.3171/2014.3. FOCUS13534

40. Buckland AJ, Ashayeri K, Leon C, et al. Single position circumferential fusion improves operative efficiency, reduces complications and length of stay compared with traditional circumferential fusion. Spine J. 2021;21(5):810-820. doi:10. 1016/j.spinee.2020.11.002

41. Oh T, Park P, Miller CA, Chan AK, Mummaneni PV. Navigation-assisted minimally invasive surgery deformity correction. Neurosurg Clin N Am. 2018;29(3):439-451. doi:10.1016/ j.nec.2018.03.002 
42. Xi Z, Chou D, Mummaneni PV, Burch S. The navigated oblique lumbar interbody fusion: accuracy rate, effect on surgical time, and complications. Neurospine. 2020;17(1):260267. doi:10.14245/ns.1938358.179

43. Kantelhardt SR, Martinez R, Baerwinkel S, Burger R, Giese A, Rohde V. Perioperative course and accuracy of screw positioning in conventional, open robotic-guided and percutaneous robotic-guided, pedicle screw placement. Eur Spine J. 2011;20(6):860-868. doi:10.1007/s00586-011-1729-2

44. Zhong J, Leon C, Ashayeri K, et al. 200. Comparison of freehand, fluoro-guided, CT navigation, and robot-guided TLIF and ALIF. Spine J. 2020;20(9):S99. doi:10.1016/j.spinee. 2020.05.611

45. Wang E, Manning J, Varlotta CG, et al. Radiation exposure in posterior lumbar fusion: a comparison of CT image-guided navigation, robotic assistance, and intraoperative fluoroscopy. Glob Spine J. 2021;11(4):450-457. doi:10.1177/ 2192568220908242

46. Rampersaud YR, Foley KT, Shen AC, Williams S, Solomito M. Radiation exposure to the spine surgeon during fluoroscopically assisted pedicle screw insertion. Spine (Phila Pa 1976). 2000;25(20):2637-2645.

47. Gwynne Jones DP, Robertson PA, Lunt B, Jackson SA. Radiation exposure during fluoroscopically assisted pedicle screw insertion in the lumbar spine. Spine (Phila Pa 1976). 2000;25(12):1538-1541. doi:10.1097/00007632-20000615000013

48. Ozgur BM, Aryan HE, Pimenta L, Taylor WR. Extreme lateral interbody fusion (XLIF): a novel surgical technique for anterior lumbar interbody fusion. Spine J. 2006;6(4):435-443. doi:10.1016/j.spinee.2005.08.012

49. Uribe JS, Arredondo N, Dakwar E, Vale FL. Defining the safe working zones using the minimally invasive lateral retroperitoneal transpsoas approach: an anatomical study. $J$ Neurosurg Spine. 2010;13(2):260-266. doi:10.3171/2010.3. SPINE09766

50. Yen CP, Uribe JS. Procedural checklist for retroperitoneal transpsoas minimally invasive lateral interbody fusion.
Spine (Phila Pa 1976). 2016;41(8):s152-s158. doi:10.1097/BRS. 0000000000001473

51. Lamartina C, Berjano P. Prone single-position extreme lateral interbody fusion (Pro-XLIF): preliminary results. Eur Spine J. 2020;29(s1):6-13. doi:10.1007/s00586-020-06303-z

52. Godzik J, Ohiorhenuan IE, Xu DS, et al. Single-position prone lateral approach: cadaveric feasibility study and early clinical experience. Neurosurg Focus. 2020;49(3):1-8. doi:10. 3171/2020.6.FOCUS20359

53. Uribe JS, Vale FL, Dakwar E. Electromyographic monitoring and its anatomical implications in minimally invasive spine surgery. Spine (Phila Pa 1976). 2010;35(26 Suppl):S368-S374. doi:10.1097/BRS.0b013e3182027976

54. Abel NA, Januszewski J, Vivas AC, Uribe JS. Femoral nerve and lumbar plexus injury after minimally invasive lateral retroperitoneal transpsoas approach: electrodiagnostic prognostic indicators and a roadmap to recovery. Neurosurg Rev. 2018;41(2):457-464. doi:10.1007/s10143-017-0863-7

Disclosures and COI: The authors received no funding for this study and report no conflicts of interest.

Corresponding Author: Themistocles S. Protopsaltis, MD, Division of Spine Surgery, Department of Orthopaedic Surgery, NYU Langone Medical Center, 333 E 38th St, 6th Floor, New York, NY 10016. Phone: (212) 598-2781; Email: Themistocles.Protopsaltis@nyulangone.org.

Published 26 October 2021

This manuscript is generously published free of charge by ISASS, the International Society for the Advancement of Spine Surgery. Copyright (C) 2021 ISASS. To see more or order reprints or permissions, see http://ijssurgery.com. 